\title{
Optimisation of Linear Passive Suspension System Using MOPSO and Design of Predictive Tool with Artificial Neural Network
}

\author{
J. NIRESH ${ }^{1 *}$, N. ARCHANA ${ }^{2}$, ANAND RAJ G. ${ }^{1}$ \\ ${ }^{1}$ Department of Automobile Engineering, PSG College of Technology, \\ Coimbatore, India, 641004 \\ nireshcbe@gmail.com (*Corresponding author), anandr0994@gmail.com \\ ${ }^{2}$ Department of Electrical and Electronics Engineering, PSG College of Technology, \\ Coimbatore, India, 641004 \\ archana.nathan31@gmail.com
}

\begin{abstract}
One of the main challenges in the design of passive suspension systems is the optimum selection of suspension system parameters. In this paper, a-four-degree-of-freedom quarter car model is implemented in order to design an optimal suspension system for better ride comfort and road holding characteristics. The mathematical model was generated in MATLAB Simulink environment for simulation. The Multi-objective particle swarm optimisation algorithm is used to optimise the suspension parameters such as suspension spring stiffness, damping coefficient of dampers, driver seat stiffness and driver seat damping coefficient. In addition, an artificial neural network model is trained to predict the root mean square values of ride comfort and road holding characteristics for a given set of input parameters by using the neural network toolbox in MATLAB. The results show that the acceleration of sprung mass and head decayed to a minimum under 2 seconds and the magnitude of the acceleration of the head was lower than that of the sprung mass. The unsprung mass was not displaced from the ground for more than $0.014 \mathrm{~m}$ and road holding characteristics were also similar.
\end{abstract}

Keywords: Suspension system, Optimisation, MOPSO, Artificial Neural Network, Simulink.

\section{Introduction}

The Automotive Industry is one of the fast growing industries with various research activities taking place to design and optimise automotive systems for an enhanced driving experience. Among them, an important system of an automobile is the suspension system which influences the vehicle stability and comfort. The suspension system can be broadly classified into two subtypes: the Active Suspension system and the Passive Suspension system. Active suspension systems can dynamically adjust the suspension characteristics according to the type of terrain while the Passive suspension systems are those with pre-determined vehicle characteristics. Therefore, the utmost consideration must be given to the design and optimisation of passive suspension systems. This type of suspension system is most commonly used in light commercial vehicles and passenger vehicles.

Many research activities have been carried out for the optimisation of passive suspension systems (Huijun et al., 2006). (Phalke and Mitra, 2016) in their work have analysed the ride comfort and road holding characteristics which are the main causes of road accidents. The analyses included the work in Simulink, by which they created a quarter car model. (Mahmoud et al., 2017) compared the performance of fully active suspension systems with that of passive suspension system both experimentally and numerically using Simulink for a quarter car model. (Gadhvi et al., 2016) in their optimisation work on passive suspension systems used multi-objective optimisation. In this case, three multi objective evolutionary algorithms such as NSGA-II, SPEA-2 and PESAII were employed and the optimisation results yielded by them were compared. (Qazi et al., 2013) approached the optimisation of semi-active suspension for a quarter car model and compared it with the passive suspension. Fuzzy logic controllers were implemented for semi-active suspension. (Gobbi et al., 2006) have carried out a theoretical investigation on the dynamic behaviour of active and passive suspension systems. The optimisation was carried out by applying the multi objective stochastic optimization method. (Tung et al., 2011) have worked on the optimisation of the active suspension mechanism of a three-degree-offreedom model using particle swarm optimisation technique. Their main goal was to optimise the stability problem of an active suspension mechanism. (Stratiskanarachos et al., 2017) have stated that about fifty thousand motorists feel that vehicle damage takes place due to pot holes on the road. For this purpose, optimisation 
of suspension system was made using Fruit Fly optimisation technique. A fuzzy logic-PSO based system was proposed by (Ghazally et al., 2019), comprising a model free based methodology. Non linear parameters were considered for minimizing vertical chassis acceleration increasing the ride comfort, thereby keeping the dynamic wheel load small in order to ensure the ride safety.

In this paper the optimisation of a passive suspension system using quarter car thorax and pelvis model of a four-degree-of-freedom system is carried out. The Optimisation is done using the Multi Objective Particle Swarm Optimisation algorithm and a Neural Network Model is designed for predicting the ride comfort and road holding characteristics of a suspension system. The quarter car model is designed using MATLAB Simulink and MATLAB Neural Network Toolbox is used to design the neural network model. Section 2 describes the methodology adopted and section 3 presents the results and discussions.

\section{Methodology}

In this paper, an analysis of suspension systems is performed in order to optimise the ride comfort and road holding by varying the suspension parameters. Sprung mass acceleration is a measure of ride comfort and the difference in road profile and unsprung mass displacement is a measure of road holding characteristics. Parameters such as suspension spring stiffness (Ks), damping coefficient of suspension dampers (Cs), stiffness of seat $(\mathrm{Kc})$ and damping coefficient of seat $(\mathrm{Cc})$ are optimised using the multi-objective particle swarm optimisation (MOPSO) method. The objective of the MOPSO algorithm is to minimise the root mean square (RMS) values of ride comfort and road holding. In addition, a neural network model is designed and trained using the input and output data obtained through the simulation of the mathematical model in MATLAB Simulink. In this analysis it is assumed that springs and dashpots have negligible mass and that they also have linear time-dependent characteristics. The passive suspension system is optimised for a bump input defined by equation (1) and the road profile is as shown in Figure 1.

$$
z x=\left\{\begin{array}{cr}
0 & \text { when } t<\frac{d}{v} \\
h * \sin \left[\frac{\pi * v}{l} *\left(t-\frac{d}{v}\right)\right] & \text { when } \frac{d}{v} \leq t \leq \frac{d+l}{v} \\
0 & \text { when } t>\frac{d+l}{v}
\end{array}\right.
$$

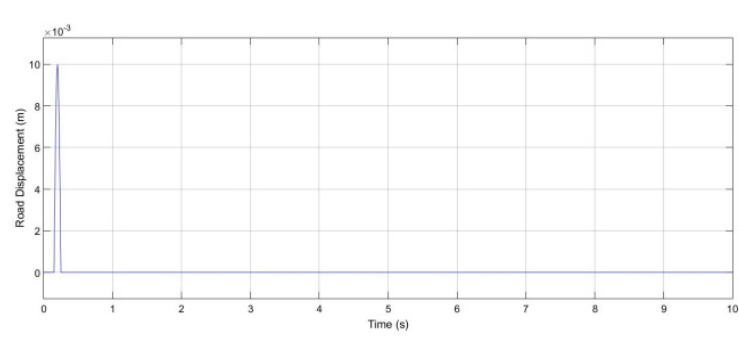

Figure 1. Road profile

\subsection{Mathematical Model}

Here the simulation is carried out for a Quarter Car Model with driver seat and driver body modelled together as four-degrees-of-freedom using spring mass damper system. In this model, the tyre has been replaced by a spring of stiffness ' $\mathrm{K}_{\mathrm{t}}$ ' and the damping is neglected. The driver seat, passenger seat, assembly of wheel, sprung mass are all modelled by a linear spring and damper in parallel and the model is as shown in Figure 2.

For this quarter car model, four equations of motion are derived by using Newton's $2^{\text {nd }}$ law of motion. Table 1 below includes the nomenclature of all the parameters and their corresponding values.

Table 1. Nomenclature and input values of all parameters

\begin{tabular}{|c|c|c|}
\hline Description & Parameters & Values \\
\hline Mass of Driver Head (Kg) & $\mathrm{Mh}$ & 5 \\
\hline Mass of body (Kg) & $\mathrm{Mb}$ & 55 \\
\hline Mass of sprung mass (Kg) & $\mathrm{Ms}$ & 290 \\
\hline $\begin{array}{c}\text { Mass of Unsprung mass } \\
(\mathrm{Kg})\end{array}$ & $\mathrm{Mu}$ & 40 \\
\hline $\begin{array}{c}\text { Stiffness of Driver body } \\
(\mathrm{N} / \mathrm{m})\end{array}$ & $\mathrm{Kb}$ & 45000 \\
\hline $\begin{array}{c}\text { Damping Coefficient of } \\
\text { Driver body }(\mathrm{Ns} / \mathrm{m})\end{array}$ & $\mathrm{Cb}$ & 1360 \\
\hline Tire Stiffness (N/m) & $\mathrm{Kt}$ & 100000 \\
\hline Bump Height $(\mathrm{m})$ & $\mathrm{h}$ & 0.01 \\
\hline Bump Width $(\mathrm{m})$ & $\mathrm{d}$ & 1 \\
\hline Vehicle Velocity (m/s) & $\mathrm{v}$ & 10 \\
\hline
\end{tabular}

The governing equations are derived from D'Alemberts principle and are expressed as (2), (3), (4) and (5).

$$
\begin{aligned}
& m_{s} * \ddot{z}_{s}=c c *(\dot{z} c-\dot{z} s)+k c *(z c-z s)-c s * \\
& (\dot{z} s-\dot{z} u)-k s *(z s-z u) \\
& m_{u} * \ddot{z}_{u}=c s *(\dot{z} s-\dot{z} u)+k s *(z s-z u)-k t * \\
& (z u-z r) \\
& m_{c} * \ddot{z}_{c}=-k c *(z c-z s)-c c *(\dot{z} c-\dot{z} s)+k b * \\
& (z h-z c)+c b *(\dot{z} h-\dot{z} c) \\
& m_{h} * \ddot{z}_{h}=-c b *(\dot{z} h-\dot{z} c)-k b *(z h-z c)
\end{aligned}
$$

https://www.sic.ici.ro 
From the governing equations described above the objective functions can be derived. Ride comfort can be measured based on the sprung mass acceleration and road holding can be measured by using the difference of unsprung mass displacement and road displacement as described by equations (6) and (7).

$$
\begin{aligned}
& \ddot{z}_{s}=\frac{1}{m_{s}}\{c c *(\dot{z} c-\dot{z} s)+k c *(z c-z s)-c s * \\
& (\dot{z} s-\dot{z} u)-k s *(z s-z u)\} \\
& (z u-z r)=\frac{1}{k t}\{c s *(\dot{z} s-\dot{z} u)+k s *(z s-z u)- \\
& \left.m_{u} * \ddot{z}_{u}\right\}
\end{aligned}
$$

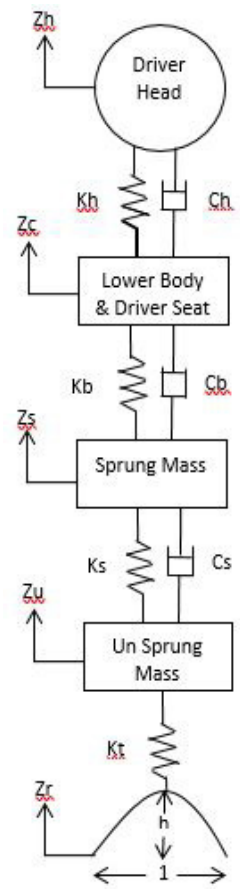

Figure 2. Thorax and pelvis model

\subsection{Simulink Model}

The quarter car thorax and pelvis model was created from the governing equations using MATLAB Simulink environment.

\subsection{Multi-Objective Particle Swarm Optimisation}

In PSO algorithm (Kennedy, 1995), the particle's initial position and velocity are randomly set. The new velocity and new position of every particle can be determined using equations (8) and (9).

$$
\begin{aligned}
& v_{i j}^{t+1}=w v_{i j}^{t+1}+c_{1} r_{1}\left(P_{b e s t i j}^{t}-x_{i j}^{t}\right)+ \\
& c_{2} r_{2}\left(g_{b e s t i j}^{t}-x_{i j}^{t}\right) \\
& z_{i j}^{t+1}=z_{i j}^{t}+v_{i j}^{t+1}
\end{aligned}
$$

where

- $\quad w$ is inertia weight,

- $\quad$ c1 and c2 are acceleration coefficients and
- $\quad \mathrm{r} 1$ and $\mathrm{r} 2$ are the uniform random numbers in the range $[0,1]$

Optimization is an iterative process and thus it converges to the global optimal solution. In single objective optimization, it is easy to calculate particle and global best values, as compared to multi-objective optimization. Due to the multiobjective nature of the problem and to the conflict between the objectives, it is quite difficult to calculate the particle and global best values. It is impossible for all objective functions to reach maximum values or minimum values at the same time. Thus, multi-objective PSO (MOPSO) (Coello et al., 2002) uses the Pareto ranking scheme to tackle the multi-objective problem. In MOPSO non-dominated solutions are stored in the repository where the records of all particles' best solutions are present. The MOPSO algorithm includes the mutation operator in order to maintain diversity in the solution space and to avoid premature convergence at some local minima.

\subsection{Artificial Neural Network}

The Artificial Neural Networks (Jain et al., 1996) are structures that connect various artificial neurons through various geometries. Their name itself indicates that artificial neurons are similar to neurons in a human brain. The neurons are cells that transmit signals throughout the human body. Likewise, the ANN system collects information from samples with neurons in them. One of the main advantages of ANN is their own decision making capability, by which they can learn the problem that is encountered.

The Artificial Neural Network consists of three layers namely, the input layer, hidden layer and output layer. The Input layer is that where input parameters are given to the network. The hidden layer is where the entire processing of input data received by the input layer is done and given to the output layer. The output layer is the final layer of the network where the data received from hidden layer are processed and the output is created. The neural network model created for this analysis consists of 10 neurons and there are 11 input parameters based on which 2 output parameters have to be determined namely the rms value of ride comfort and the rms value of road holding. The model was trained using the Leven-Marquardt 
algorithm along with the Neural Network toolbox in MATLAB and it is shown in Figure 3.

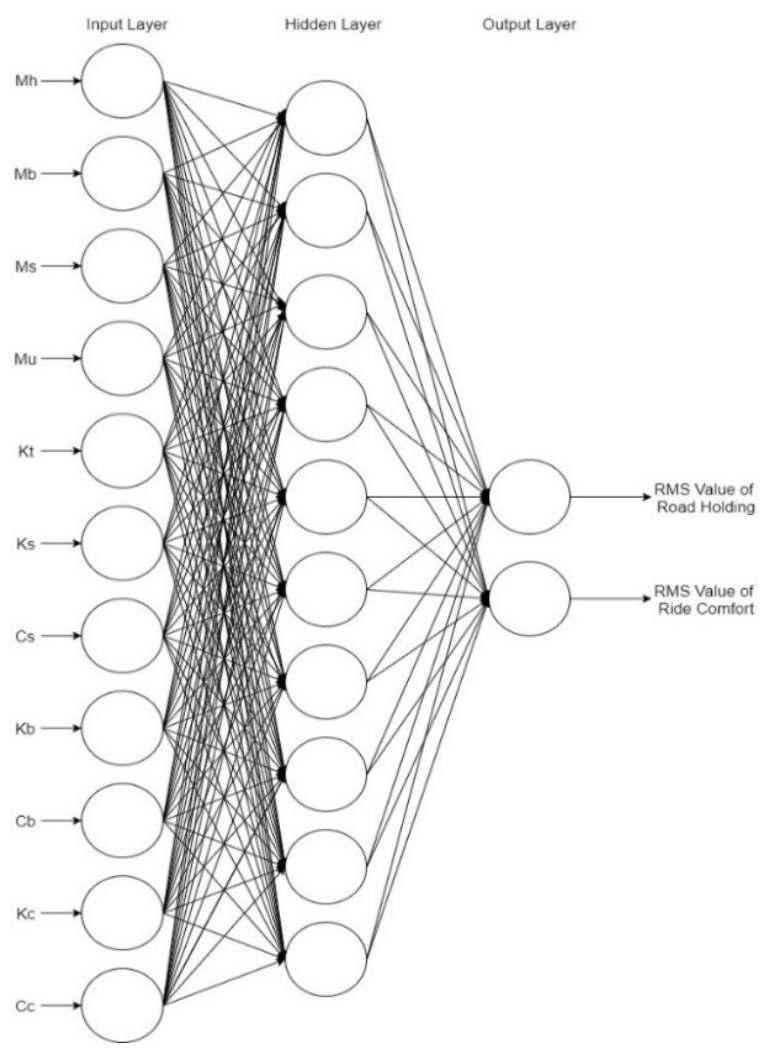

Figure 3. ANN Model

\section{Results}

The MOPSO algorithm produced convergence with a population size of 25 in 39 iterations and further iterations caused minor changes in the values of the objective function. The mutation operator used with this optimisation algorithm avoids premature convergence at local minima and therefore it is safe to say that the obtained results are converged at the global minima. The repository matrix stores the best positions of particles during all the iterations and at $50^{\text {th }}$ iteration 37 optimised points were generated.

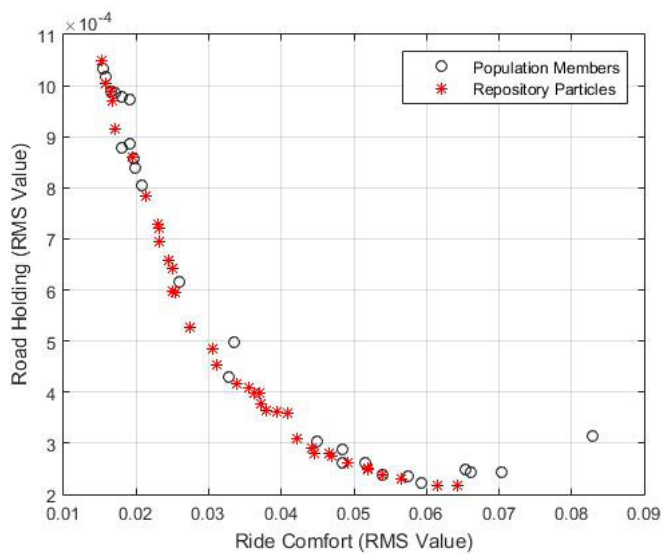

Figure 4. Pareto front
Figure 4 illustrates the Pareto front generated at the 50th iteration which shows all the population members and repository particles in the search space. Here the rms value of ride comfort is taken along the $\mathrm{X}$-axis and the rms value of Road Holding along Y-axis. It can be inferred from this graph that both ride comfort and road holding are inversely proportional. Thus, an optimal value satisfying the required ride comfort and road holding can be selected from the Pareto front. The selected optimal values obtained from the Pareto front are displayed in Table 2.

Table 2. MOPSO Parameters

\begin{tabular}{|c|c|c|}
\hline Sl. No & Parameter & Values \\
\hline 1 & Number of decision variables & 4 \\
\hline 2 & Maximum iterations & 50 \\
\hline 3 & Population size & 25 \\
\hline 4 & Inertia weight & 0.5 \\
\hline 5 & Inertia weight damping factor & 0.99 \\
\hline 6 & Personal learning coefficient & 1 \\
\hline 7 & Global learning coefficient & 2 \\
\hline 8 & Mutation rate & 0.1 \\
\hline
\end{tabular}

Table 3. Optimised values of suspension parameters

\begin{tabular}{|c|c|c|}
\hline Description & $\begin{array}{c}\text { Variable } \\
\text { Name }\end{array}$ & Value \\
\hline $\begin{array}{c}\text { Damping Coefficient of Driver } \\
\text { body (Ns/m) }\end{array}$ & $\mathrm{Cb}$ & 1360 \\
\hline Stiffness of Driver Body (N/m) & $\mathrm{Kb}$ & 45000 \\
\hline Tire Stiffness (N/m) & $\mathrm{Kt}$ & 100000 \\
\hline Mass of Driver Head (Kg) & $\mathrm{Mh}$ & 5 \\
\hline Mass of body (Kg) & $\mathrm{Mb}$ & 55 \\
\hline Mass of sprung mass (Kgs) & $\mathrm{Ms}$ & 290 \\
\hline Mass of Unsprung mass (Kgs) & $\mathrm{Mu}$ & 40 \\
\hline $\begin{array}{c}\text { Damping Coefficient of seat } \\
\text { (Ns/m) }\end{array}$ & $\mathrm{Cc}$ & 3386.2896 \\
\hline $\begin{array}{c}\text { Damping Coefficient of } \\
\text { Suspension Spring (Ns/m) }\end{array}$ & $\mathrm{Cs}$ & 498.69401 \\
\hline $\begin{array}{c}\text { Stiffness of Seat (N/m) } \\
\text { (N/m) }\end{array}$ & $\mathrm{Kc}$ & 6592.8504 \\
\hline $\begin{array}{c}\text { Stiffness of Suspension Spring } \\
\text { Ks }\end{array}$ & 3996.8891 \\
\hline
\end{tabular}

With the optimised values described in Table 3 the mathematical model was simulated in MATLAB Simulink environment. In Figure 5 it can be seen that the acceleration of sprung mass decays to a minimum after 1 second and a maximum acceleration of $0.86 \mathrm{~m} / \mathrm{s}^{2}$ is produced. By comparing Figure 5 to Figure 6 it can be observed that much of the vibration is damped as the maximum head acceleration is less than 
$0.8 \mathrm{~m} / \mathrm{s}^{2}$ however the decay of acceleration is at a lesser rate when compared with that of the sprung mass.

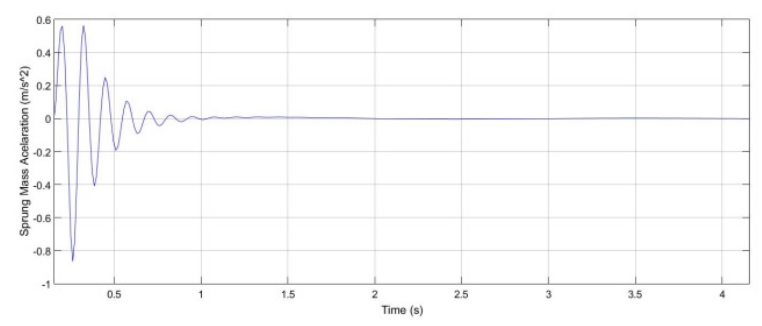

Figure 5. Sprung mass acceleration

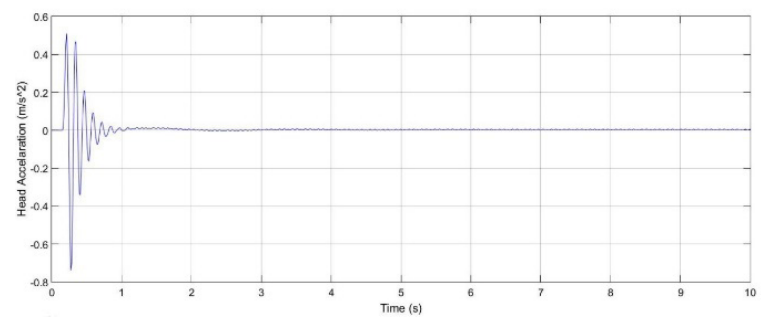

Figure 6. Head acceleration

Figure 7 illustrates the road holding characteristics of the vehicle and it shows a maximum value of $0.009 \mathrm{~m}$ deviation from the ground whereas in Figure 8 the unsprung mass displacement shows a maximum value of $0.014 \mathrm{~m}$ from ground, while the rate of decay of unsprung mass displacement is similar to the road holding characteristics and it falls to a minimum at less than 2 seconds thus enhancing stability of the vehicle.

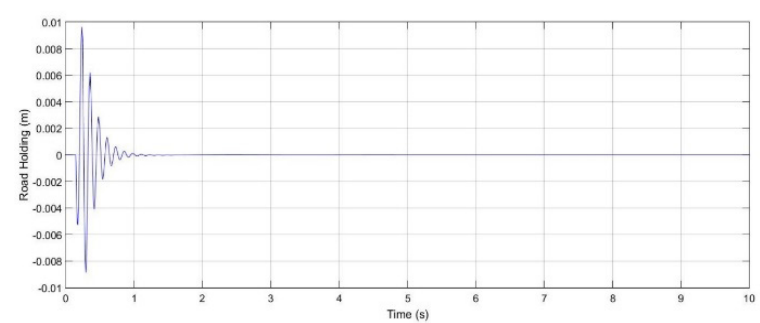

Figure 7. Road holding

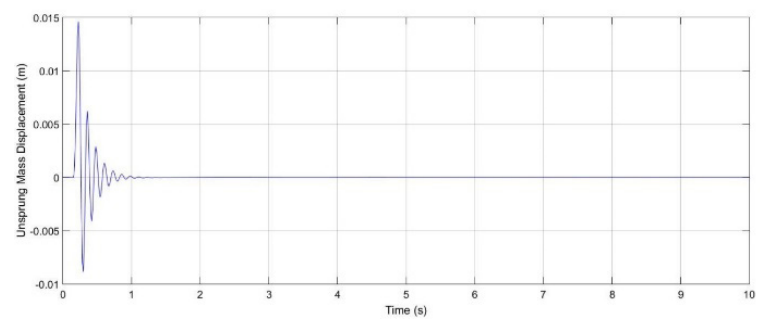

Figure 8.Unsprung mass displacement

For the considered sprung and unsprung mass, the performnace in terms of the body acceleration and displacement is better than that obtained by the already available methods in the literature namely PID, iPID, TDEC, and Fuzzy based model (Ghazally et al., 2019,). The neural network model was trained to predict the rms values of ride comfort and road holding by using all the suspension system parameters namely Kt, Ks, Cs, $\mathrm{Kc}, \mathrm{Cc}, \mathrm{Kb}, \mathrm{Cb}, \mathrm{Mh}, \mathrm{Mb}$, Ms and $\mathrm{Mu}$. The error histogram and regression curves were generated using the neural network toolbox in MATLAB. The predicted results of the neural network model were close to the target data which can be inferred from Figure 9 and the trained neural network model also produced an approximate fit with an overall regression coefficient (R) of 0.99965 as shown in Figure 10. From the error histogram and regression curves it can be inferred that ithe above-metioned model predicted the results with considerable accuracy.

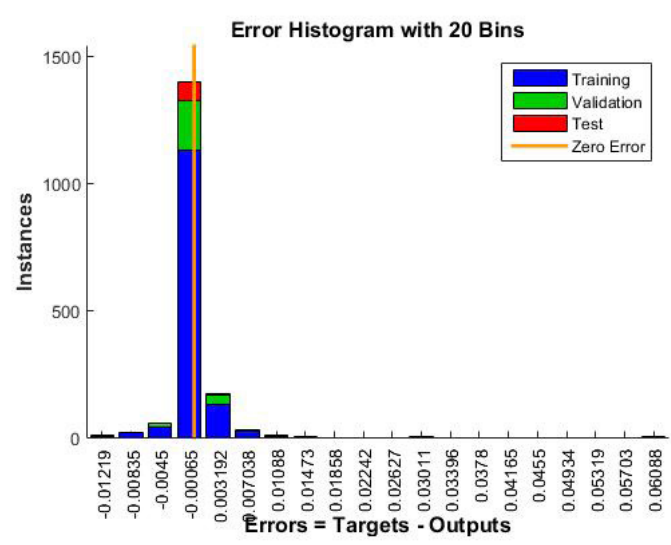

Figure 9. Error histogram of the trained neural network model
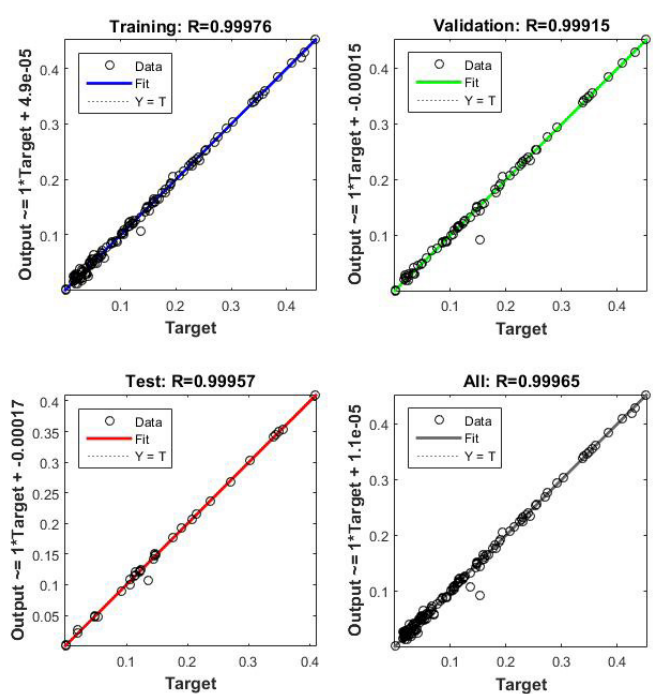

Figure 10. Regression curves of the trained neural network model 


\section{Conclusion}

A quarter car thorax and pelvis model with four degrees of freedom was implemented to optimise the parameters of a passive suspension system by using the multi-objective particle swarm optimisation method for maximising ride comfort and road holding. Optimisation was done for a given set of parameters such as mass of the bodies, tire stiffness and body stiffness and damping coefficient. The corresponding values of optimum suspension parameters were obtained by using the multi-objective particle swarm

\section{REFERENCES}

1. Abroon Jamal Qazi, Umar A. Farooqui, Afsal Khan, M. Tahir Khan, Farrukh Mazhar \& Ali Fiaz (2013). Optimisation of Semi-Active suspension system using Particle Swarm Optimisation Algorithm. In Proceedings of the AASRI Conference on Intelligent Systems and Control, 4 (pp. 160-166).

2. Bhargav Gadhvi, Vimal Savsani \& Vivek Patel (2016). MultiObjective Optimisation of vehicle passive suspension system using NSGA-II, SPEA2 and PESA-II. In Proceedings of the International Conference on Innovations in Automation and Mechatronics Engineering, Procedia Technology, 23 (pp. 361-368).

3. Coello Coello C. A. \& Lechuga, M. S. (2002). MOPSO: a proposal for multiple objective particle swarm optimization. In Proceedings of the 2002 Congress on Evolutionary Computation, 2 (pp. 1051-1056).

4. Gao Huijun, Lam James \& Wang Changhong (2006). Multi-Objective Control of Vehicle Active Suspension Systems via LoadDependent Controllers, Journal of Sound and Vibration, 290, 654-675.

5. Ghazally I. Y., Mustafa, H. P. Wang \& Yang Tian (2019). Vibration control of an active vehicle suspension systems using optimized model-free fuzzy logic controller based on time delay estimation, Advances in Engineering Software, 127, 141-149.

6. Hac, A. (1985). Suspension optimization of a 2-dof vehicle model using a stochastic optimal control technique, Journal of Sound and Vibration, 100(3), 343-357.

7. Jain, A. K., Jianchang Mao \& Mohiuddin, K. M. (1996). Artificial neural networks: a tutorial, Computer, 29(3), 31-44. optimisation algorithm. The results show that the acceleration of sprung mass and head decayed to a minimum under 2 seconds and the magnitude of the acceleration of the head was lower than that of the sprung mass. The unsprung mass was not displaced from the ground for more than $0.014 \mathrm{~m}$ and road holding characteristics were also similar. A neural network model was trained by using the Leven-Marquardt algorithm from a set of inputs for predicting the rms values of road holding and ride comfort. The trained model predicted the results with a considerable accuracy and produced a good fit with an overall regression coefficient of 0.99965 .

8. Kennedy, J. (2011). Particle Swarm Optimization. In Sammut C. \& Webb G. I. (eds.), Encyclopedia of Machine Learning. Springer, Boston, MA.

9. Mahmoud Omar, El-Kassaby M. M. \& Walid Abdelghaffar (2017). A universal suspension test rig for electro hydraulic active and passive automotive suspension system, Alexandria Engineering Journal, 56(4), 359-370.

10. Massimiliano Gobbi, Francesco Levi \& Giampiero Mastinu (2006). Multi Objective stochastic optimisation of the suspension system of road vehicles, Journal of Sound and Vibration, 298(4-5), 1055-1072.

11. Shen-Lung Tung, Yau-Tarng Juang, WeiHsun Lee, Wern-Yarng Shieh \& Wei-Ying Wu (2011). Optimisation of the exponential stabilization problem in active suspension system using PSO, Expert Systems with Applications, 38(11), 14044-14051.

12. Stratis Kanarachos, Arash Moradinegade Dizqah, Georgios Chrysakis \& Michael E. Fitzpatrick (2017). Optimal design of a quadratic parameter varying vehicle suspension system using contrast-based fruit fly optimisation, Applied Soft Computing, 62, 463-477.

13. Tewari, V. K. \& Prasad, N. (1999). ThreeDOF modeling of tractor seat operator system, Journal of Terramechanics, 36(4), 207-219.

14. Trupti P. Phalke \& Anirban C. Mitra (2017). Analysis on ride comfort and road holding of quarter car model using Simulink. In Proceedings of the International Conference on Material Processing and Characterization, 4(2) (pp. 2425-2430). 